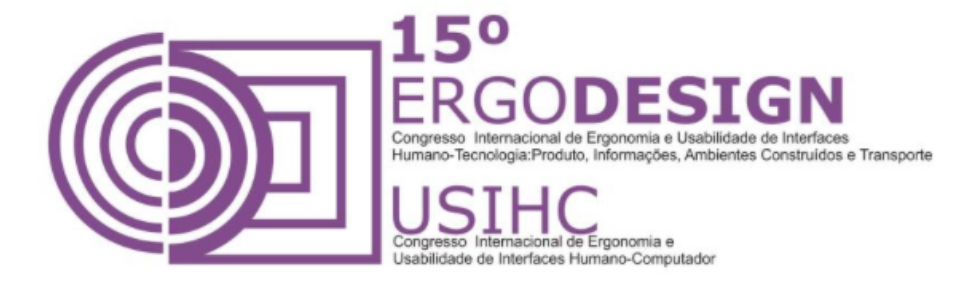

\title{
ANÁLISE DE USABILIDADE DA HOMEPAGE DE UM EQUIPAMENTO DE ELETROENCEFALOGRAMA: EMOTIV EPOC
}

\section{USABILITY ANALYSIS OF AN ELECTROENCEPHALOGRAM HOMEPAGE EQUIPMENT: EMOTIV EPOC}

\author{
BARROS, Rafaela Queiroz de (1); \\ SANTOS, Gabriele M. Silva dos(2); \\ SANTOS, Caroline Patrícia Ribeiro (3); \\ TORRES, Rebeca Monteiro (4) \\ SOARES, Marcelo Marcio (5)
}

Universidade Federal de Pernambuco

(1) (2) Mestrandas em Design

e-mails: queirozdebarros@hotmail.com,gabriele.sant@hotmail.com

(3) (4) Graduandas em Design

e-mails: carol.rib.design@gmail.com, rebecatorrez@gmail.com

(5) Ph.D. em Ergonomia

\begin{abstract}
RESUMO
O presente artigo buscar introduzir a análise de usabilidade da webpage do Emotiv EPOC, um revolucionário equipamento de análise cerebral. Este equipamento tem a habilidade de controlar objetos com a força do pensamento e consegue interagir com a interface computador $x$ humano. Além do mais, ele pode detectar pensamentos, sentimentos, expressões faciais via conexão wireless. Utilizamos como apoio para este trabalho, as Dez Orientações da Web de Brinck, T.,Gergle, D. and Wood, S.D. (2002), a Avaliação Heurística segundo os critérios de Nielsen (1993) e o modelo de Lebenthal e Barnes (2008). Foram identificamos alguns problemas de usabilidade na homepage e soluções foram recomendadas. .
\end{abstract}

Palavras-chave: Usabilidade, Emotiv EPOC, website e ergonomia.

\begin{abstract}
This article seek to introduce the website of the usability analysis of the Emotiv EPOC, a revolutionary equipment brain analysis. This equipment has the ability to control objects with the power of thought and can interact with the computer human interface $x$. Moreover, it can detect thoughts, feelings, facial
\end{abstract}




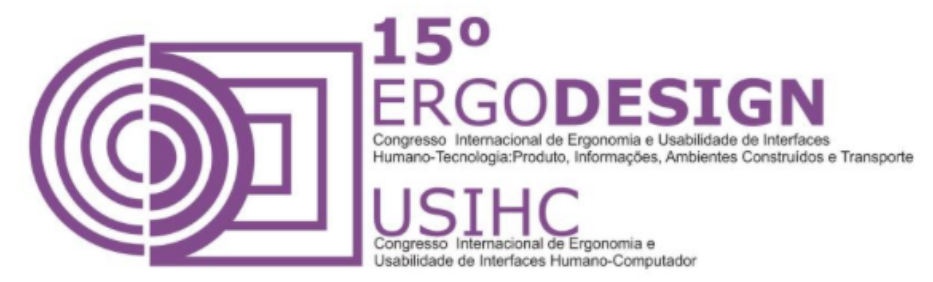

expressions via wireless connection. Used as support for this work, the Web Guidelines Ten Brinck, T., Gergle, D. and Wood, SD (2002), the heuristic evaluation according to Nielsen criteria (1993) and the model of Lebenthal and Barnes (2008). We identified some usability issues on the homepage and solutions were recommended.

Keywords:Usability, Emotiv EPOC, website and ergonomics.

\section{INTRODUÇÃO}

Atualmente o acesso a web tornou-se uma prática muito frequente no cotidiano das pessoas e está a cada dia mais em destaque em razão da necessidade de atrair a atenção dos usuários de produtos e serviços e proporcionar mais aplicações para o seu dia a dia, além de ser uma importante ferramenta de suporte e venda empresarial.

Diante deste cenário, as empresas se preocupam em ampliar o contato com o seu público utilizando-se, para isto, da Web como uma ferramenta de criação de plataformas multimidiáticas como homepages, redes sociais e outros canais de negócios, marketing, comunicação e suporte para os seus produtos. Isto faz parte do desenvolvimento de estratégias para aumentar a visibilidade e o conhecimento da sua marca proporcionando uma melhoria na venda de seus produtos.

Sendo assim, caso o usuário encontre algum tipo de dificuldade de navegação ao utilizar a página eletrônica de uma determinada empresa ou produto, será possível que ele ou ela não se sinta confortável em ter esta experiência frustrante e talvez não queira repeti-la. Esta situação ocorre principalmente quando os sites apresentam falhas de usabilidade para as tarefas necessárias e importantes. Com a facilidade do acesso as informações da internet, os usuários estão mais experientes com a interação de navegação e cada vez menos tolerantes a sites complexos e difíceis de usar. Estes querem acessar rapidamente o conteúdo que desejam, de forma clara, rápida e direta. Desta maneira, muitos estudos utilizam a avaliação da usabilidade como um método sistemático de análise das interações do usuário com o produto e/ou sistemas buscando encontrar os possíveis problemas e tratá-los com princípios de usabilidade.

A proposta do estudo foi de realizar uma análise de usabilidade da homepage emotiv.com de um equipamento de Eletroencefalograma (EEG), conhecido como Emotiv EPOC através de métodos para avaliação de software. Este equipamento é um capacete formado por 14 canais de dados que estão dispostos através de hastes com sensores que funcionam por meio da captação dos sinais elétricos cerebrais. Os sensores do capacete são posicionados no escalpo do indivíduo e o registro dos sinais detectados são amplificados e processados em tempo real.

O Emotiv EPOC tem a habilidade de controlar objetos com a força do pensamento e consegue interagir com a interface computador $x$ humano. Além do mais, ele pode detectar pensamentos, sentimentos, expressões faciais via conexão wireless.

Para tanto, a primeira etapa da pesquisa consistiu de uma inspeção de usabilidade por meio da avaliação heurística realizada por 5 especialista da área de web. Já na segunda etapa foi aplicado um checklist com base nas das Dez Orientações da Web de Brinck, T.,Gergle, D. and 


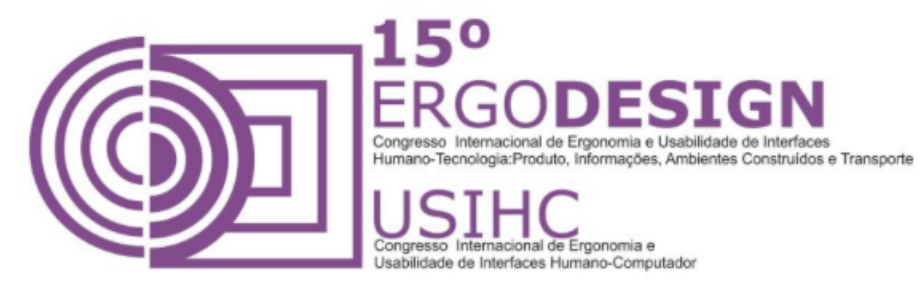

Wood, S.D. (2002) executada pelos pesquisadores. Ao final, os dados coletados nas duas avaliações foram confrontados, sendo gerados os resultados e as sugestões de melhoria para 0 website.

Neste artigo analisamos o site a partir do modelo de Leventhal e Barnes (2008) e na avaliação Heurística segundo os critérios de Nielsen (1993). Sendo assim, algumas recomendações foram apresentadas de acordo com os problemas encontrados na pesquisa.

\section{PROCEDIMENTOS METODOLÓGICOS}

O conceito da usabilidade está relacionado com a interação humano-computador $(\mathrm{HCl}-\mathrm{Human}$ Computer Interaction) que é empregado no aperfeiçoamento da interface usuário-software. A usabilidade "influencia" na escolha de um determinado artefato e propõe interfaces com o nível de relacionamento adequado com o usuário (FALCÃO E SOARES, 2012).

Neste sentido, segundo Leventhal e Barnes (2008), a usabilidade pode ser conduzida de forma a facilitar o uso de avaliações e testes de usabilidade, contudo, diferentes abordagens para a avaliação da usabilidade são propostas em diferentes contextos. Sendo assim, foi realizada uma análise de usabilidade da homepage do equipamento EEG Emotiv EPOC composta por métodos não empírico, ou seja com a análise de especialistas.

A análise de usabilidade é realizada através da reunião de informações a respeito das situações particulares dos produtos de consumo em questionamento (ROEPKE, 2012). A metodologia desta pesquisa foi constituída de acordo com os seguintes procedimentos metodológicos:

Na primeira etapa foi analisada a interação do usuário com a homepage utilizando os princípios de design de interação, diretrizes gerais para o design e diretrizes para o design visual (Leventhal e Barnes, 2008).

Posteriormente, na segunda etapa, foi realizada uma avaliação de usabilidade de acordo com as heurísticas de Nielsen (1993) que contribuem para a identificação de erros no site analisado. Para isto, foi aplicado um checklist contendo respostas abertas e orientações sobre o seu preenchimento. Para cada problema encontrado o avaliador preenche seis diferentes colunas sobre Severidade, Exemplo do local, Heurística, Elemento, Descrição do Problema e Sugestão.

Para esta análise heurística, foram selecionados cinco profissionais designers de interface e/ou interação com experiência em projetos de web. Estes receberam por e-mail a avaliação em formato de um checklist seguido de algumas orientações para o procedimento da avaliação. Após realizar o preenchimento, os participantes enviaram por e-mail o arquivo para os pesquisadores, para que os resultados fossem analisados de acordo com os problemas identificados.

$\mathrm{Na}$ terceira etapa foi desenvolvida uma análise de software. Para isto, cinco especialistas 


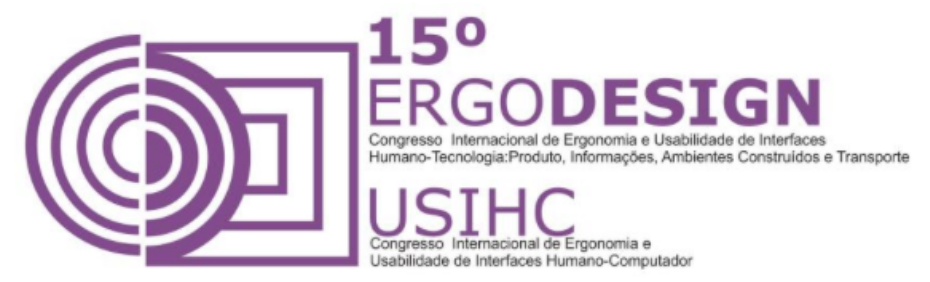

realizaram um checklist de acordo com as Dez Orientações da Web de Brinck, Gergle e Wood (2002) em relação ao site emotiv.com.

Finalmente, os resultados das avaliações de usabilidade do website foram comparados e analisados, de acordo com as duas metodologias mencionadas para serem realizadas recomendações ou sugestões.

\subsection{Análise de interação do usuário e das diretrizes gerais para o design}

O projeto global do site emotiv.com foi analisado em relação ao design de interação do usuário, que se preocupa com a usabilidade da interface e as interações individuais. Ou seja, nesta etapa foi observada a forma como o usuário interage com a homepage a partir do ponto de vista dos pesquisadores.

Sendo assim, o site emotiv.com oferece aos usuários um estilo de interação baseados em manipulações de objetos visuais. Para isto, na página inicial (Figura 1) o menu principal é fixo na área superior da página que é apresentada por ícones contendo menus do tipo pull down com diferentes opções de informações.

Na mesma barra principal, existem outros ícones que quando acessados são direcionados para a página com o conteúdo respectivo ao ícone selecionado.

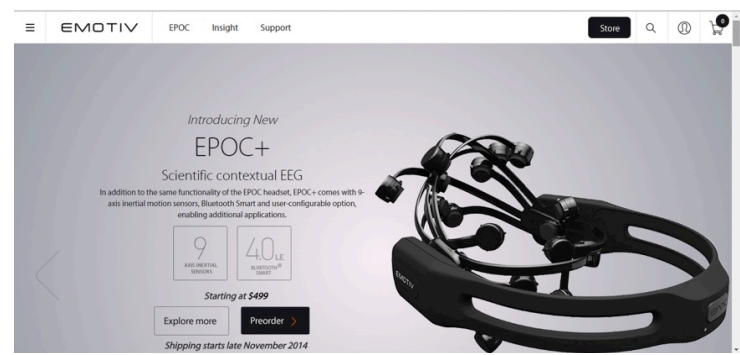

Figura 1. Página inicial da homepage emotiv.com

No caso do acesso ao usuário, um formulário de registro (Figura 2) é oferecido para criar uma conta e senha para o usuário. Para tanto, faz-se necessário preencher os campos vazios do formulário. Já a opção do carrinho de compras somente é acessada com o nome da conta do usuário e senha criados. Em relação ao atendimento ao usuário, é disponibilizado um ícone de pesquisa (Figura 3) que atende por interação de perguntas e respostas. Ao final da página e no canto inferior há um menu com uma listagem de tópicos divididos por categorias de

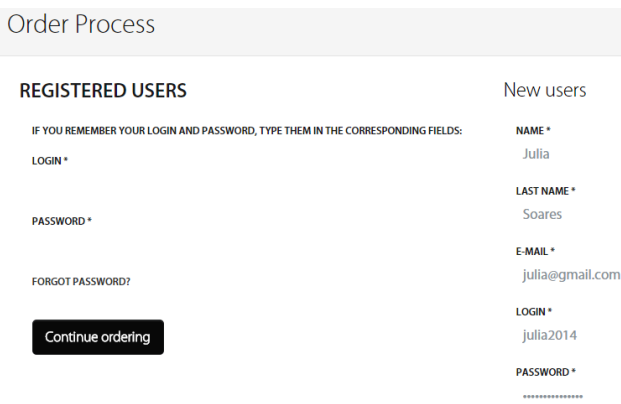




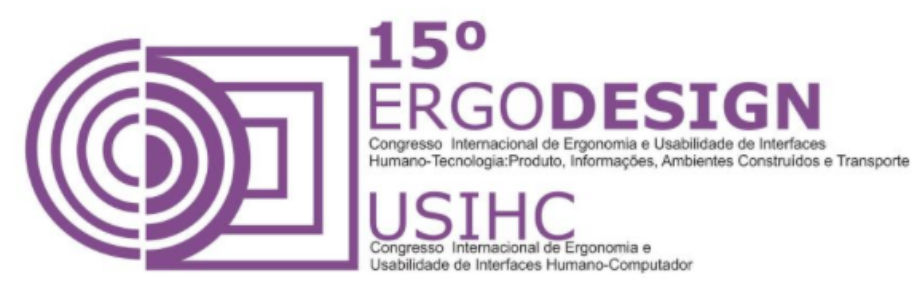

informações.

Figura 2. Página de registro para novos usuário.

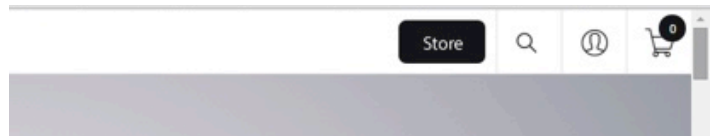

Figura 3. Ícone de pesquisa, login e compras, localizado na barra superior do site.

Através destas informações, o estudo foi realizado a partir do acesso e disponibilidade do website aos usuários. É valido comentar que um dos aspecto de interesse desta pesquisa também foi em relação aos pesquisadores terem a oportunidade de analisarem o site de um equipamento que tem como base os conhecimentos da neurotecnologia e que realiza medições de sinais de EEG e os armazena em um arquivo de software.

O site do equipamento Emotiv atende as seguintes diretrizes gerais de design:

- Utiliza modelos mentais viáveis semelhantes ao funcionamento de outros sites, como também terminologias e ações de forma consistente.

- Utiliza analogias e metáforas significativas por meio de ícones de fácil identificação e associação às atividades que estão relacionadas, como por exemplo o ícone do carrinho de compras que oferece a opção de compras dos equipamentos do site ou a lupa, como ícone de busca no site. As metáforas utilizadas são apropriadas as tarefas dos usuários.

- Não utiliza figuras antropomórficas que distraem a atenção do usuário em relação à tarefa.

- Oferece a redução da carga de trabalho cognitivo através do destaque das informações principais localizadas na barra de menu principal que facilita o acesso do usuário aos interesses principais, tais como: informação sobre produtos, suporte, pesquisa, login e compra. As barras de menus permitem ao usuário identificar e realizar rapidamente a atividade que deseja de forma direta.

- Nenhuma das ações que acontecem no site são realizadas sem a autonomia do usuário. Os links, vídeos e downloads, por exemplo, são realizados apenas através do comando do internauta.

Em relação ao projeto da webpage do site em questão, as seguintes diretrizes para o design visual foram identificadas:

- Uso da Cor: As cores utilizadas no primeiro plano são cores neutras, tais como, branco, preto e tons de cinza. A escolha das cores contrasta as informações sobre produto. Também são utilizadas em segundo plano as cores azul e laranja para os itens que merecem destaque, como preços e links. Essas cores atendem ao contraste fundamental para a capacidade de distinguir cores, selecionar e visualizar as informações/conteúdo do site. 


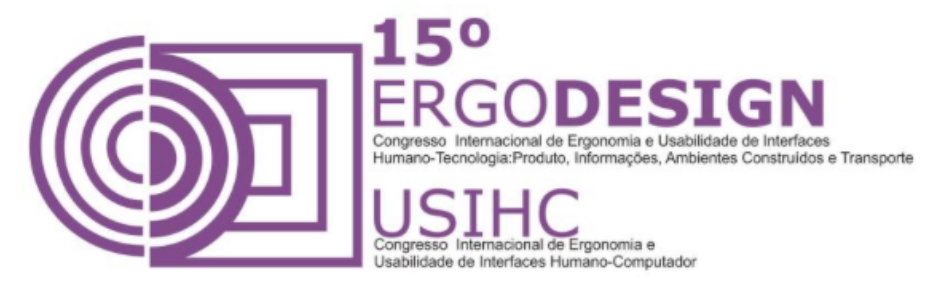

- Uso de fontes: O site utiliza apenas uma fonte sem serifa, com variações de formato em Regular, Bold, Italic e Bold Italic. O texto apresenta diferentes tamanhos de fonte para 0 título, o subtítulo e o conteúdo do texto. Adicionalmente, o conteúdo do texto possui variações de tamanho de fontes que destaca as principais informações.

- Contraste dos planos de frente/fundo: O site possui contraste suficiente entre o background e as informações, sendo possível a visualização das cores apresentadas em preto e branco (cores presentes na maior parte do site), pelo público que tenha deficiência com cores, como os daltônicos.

- Uso de gráficos: A homepage não possui gráficos. Porém são utilizadas etiquetas com informações que quando acessadas são direcionadas ao conteúdo. Estas etiquetas estão presentes principalmente nos botões e legendas dos ícones.

- Atraindo a atenção para elementos menos importantes da interface: O site apresenta cores com a combinação e o destaque adequados para as informações mais importantes, que atraem a atenção do leitor.

- Uso de símbolos: Os símbolos apresentados estão relacionados a metáforas adequadas para os respectivos conteúdos. Os símbolos são apresentados para representar características do produto e ações do usuário.

\subsection{Avaliação de usabilidade}

A avaliação de usabilidade de acordo com as heurísticas de Nielsen (1993) foi realizada por 5 profissionais da área web, que desempenham atividades de design de interação e/ou design de interfaces. Nenhum dos participantes possuía conhecimento prévio sobre o site avaliado, ou mesmo conhecimentos detalhados sobre o Emotiv EPOC, porém todos eles já possuíam conhecimento sobre as 10 heurísticas de Nielsen (1993):

Diante deste contexto, a compilação dos resultados das avaliações realizadas pelos 5 profissionais, é detalhado a seguir:

\section{Controle e liberdade para o usuário}

- Redimensionamento da janela do browser (Severidade - Maior): A janela do browser é dimensionada de forma inadequada. Em outras palavras, os elementos de vídeo, texto e imagens são apresentados em dimensão maior que a área visual da tela. Não há opção de adequação da tela para a visualização do campo visual ou do tamanho da janela (Figura 3).

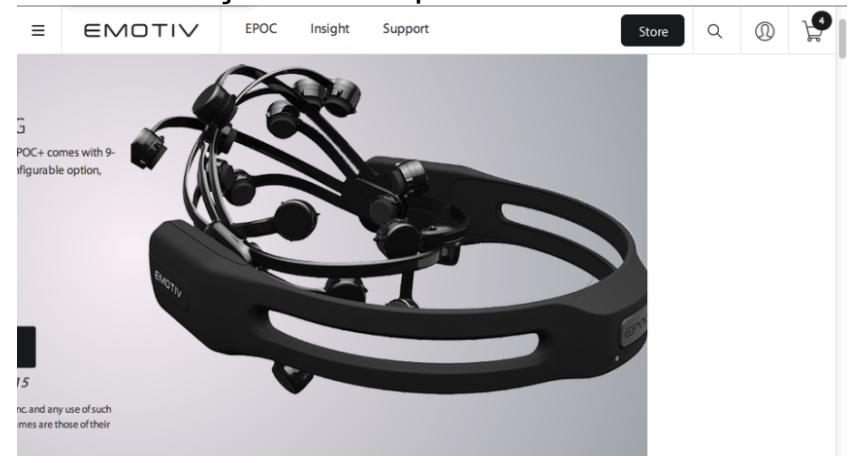




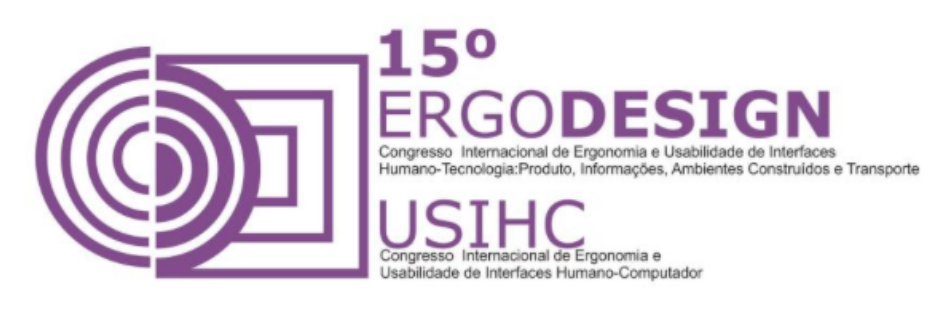

Figura 3. Identificação de falha no layout após redimensionar a janela do browser.

\section{Consistência e padrões}

1. Comportamento do menu suspenso (Severidade - Menor): Não é possível fechar o menu ao clicar fora dele (Figura 4).

2. Mudança de ícone no menu suspenso (Severidade - Menor): Apenas o primeiro ícone do menu é alterado quando o menu suspenso aparece (Figura 4).

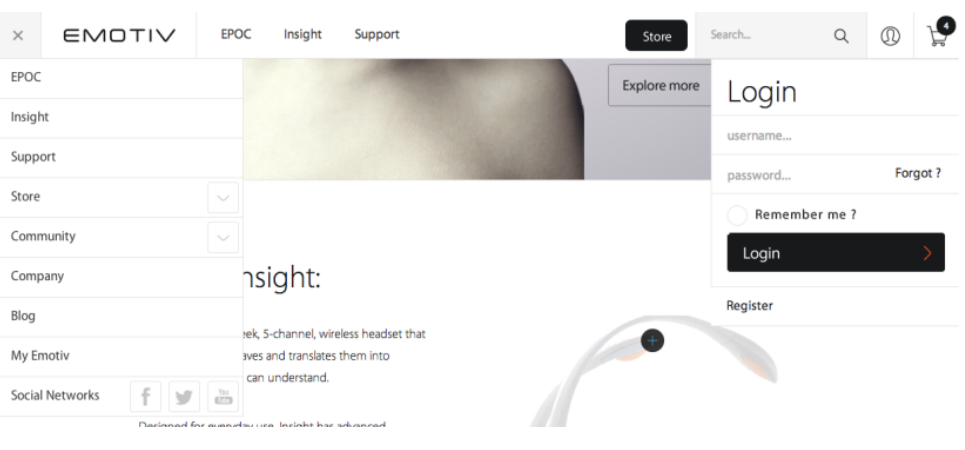

Figura 4. Menus suspensos.

3. Vídeos apresentam falhas de execução (Severidade - Maior): Alguns vídeos não funcionam. Sendo assim, as miniaturas e vídeos não são exibidos.

4. Campos de input de texto indefinidos (Severidade - Menor): Alguns campos de texto não possuem clareza e feedback quanto ao local para a digitação.

\section{Reconhecimento em lugar de lembrança}

1. Botões sem contraste (Severidade - Menor): Os botões "+" que estão localizados sob os sensores do equipamento Emotiv EPOC têm a função de apresentar informações sobre o produto. As informações aparecem com o movimento do cursor em cima da figura.

Outro aspecto analisado é que as cores do contraste da figura não são suficientes para uma boa visualização da função dos botões "x". Este problema pode levar ao usuário não utilizar esta função ou esquecê-la (Figura 5).

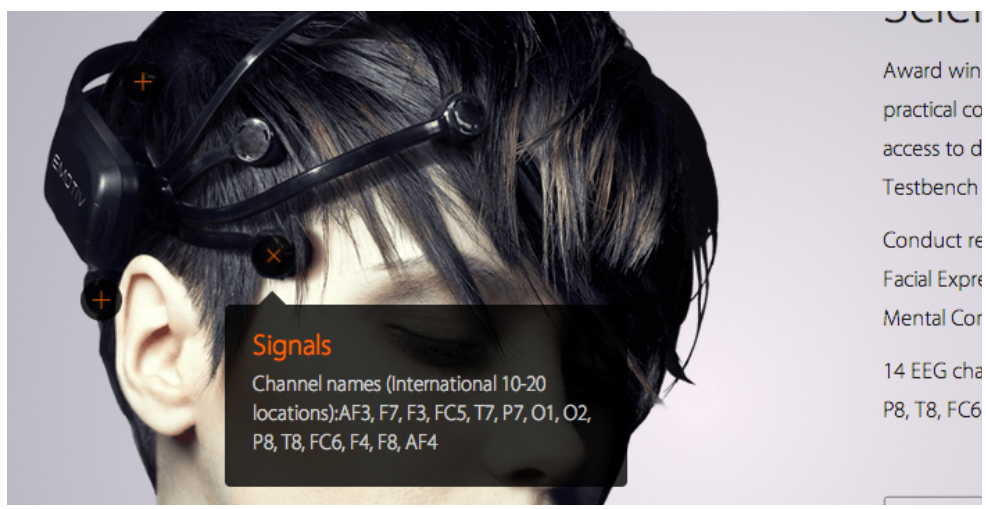




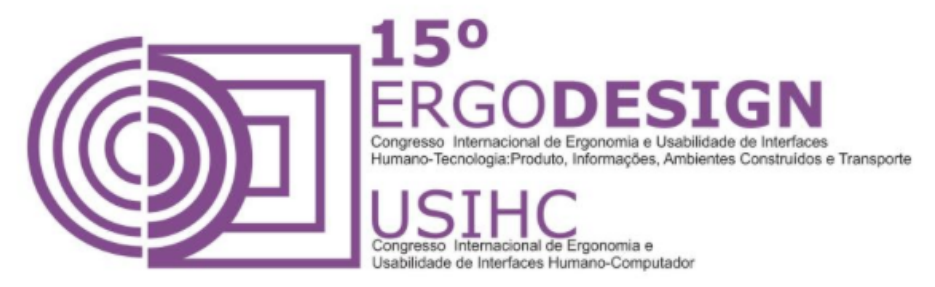

Figura 5. Contraste insuficiente para uma boa visualização da função dos botões "x".

\section{Flexibilidade e eficiência de uso}

1. O link para contatos não funciona (Severidade - Maior): Na seção de suporte, o link para contatos por e-mail não funciona.

2. A pesquisa por suporte não funciona (Severidade - Maior): No campo de pesquisa é possível digitar, mas não são apresentados resultados para a pesquisa.

\section{Design minimalista e estético}

1. Seta de Navegação do Banner (Severidade - Cosmético): A figura da seta de navegação entre os banners na página inicial não possui destaque visual e pouco contraste. Algumas imagem apresentadas neste caso não são possíveis de visualizar (Figura 6).

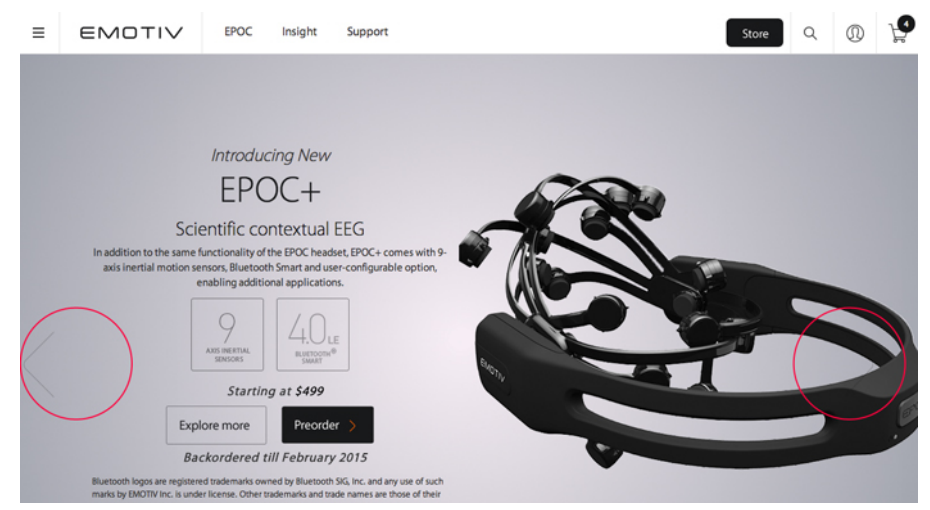

Figura 6. Os círculos em vermelho representam as setas de navegação com pouco contraste.

2. Recorte e imagens serrilhadas (Severidade - Cosmético): O recorte das imagens dos dois produtos que aparecem no banner principal são apresentados com o contorno irregular dos pixels.

\section{Reconhecimento, diagnóstico e recuperação de erros pelos usuários}

1. O Campo disponível para acessar o login não oferece feedback ao usuário (Severidade Maior): Não há mensagem de erro de digitação ou feedback para o cliente que deseja utilizar o espaço para o login da home.

Através da análise dos resultados da avaliação de usabilidade, segundo Nielsen (1993) foi possível detectar problemas em 6 das 10 heurísticas. A maior parte dos problemas foram avaliados com severidade de grau Menor. Ao todo, os avaliadores identificaram 11 problemas.

Segundo as dez orientações para web Brinck, Gergle e Wood (2002), foi possível desempenhar 


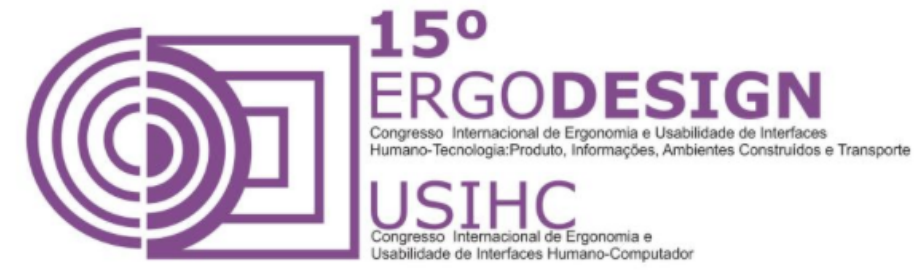

a avaliação da homepage emotiv.com com a participação de cinco especialistas no uso de sites da internet. Os resultados do diagnóstico dos avaliadores foram organizados na tabela 1 e classificados de acordo com cada uma das dez orientações da Web:

Orientações

Conteúdo e escopo
Diagnóstico

Apresenta as funcionalidades necessárias para atender ao usuário. As informações sobre o produto são fornecidas por meio de texto, imagens e vídeos explicativos e demonstrativos, possibilidade de compra dos produtos, fórum, pesquisa e suporte. As informações principais estão de fácil acesso na página inicial.
Classificação

Atende

A velocidade de carregamento das páginas é rápida, de acordo com a qualidade de conexão da internet, mesmo no carregamento de algumas

Atende imagens que aparecem como background.

\begin{tabular}{lll}
\hline $\begin{array}{l}\text { Adequação à } \\
\text { tarefa }\end{array}$ & $\begin{array}{l}\text { O site destaca as principais tarefas oferecidas já } \\
\text { na página inicial. Destaca opções para acessar as } \\
\text { informações diretas sobre os dois produtos } \\
\text { principais, acessar a loja, pesquisar, login e } \\
\text { carrinho de compras. }\end{array}$ & Atende \\
\hline Simplicidade & $\begin{array}{l}\text { O site possui volume de informação adequada e } \\
\text { evita textos e informações desnecessários. } \\
\text { Destaca alguns temas de forma objetiva e } \\
\text { simples. }\end{array}$ & Atende \\
\hline $\begin{array}{l}\text { Não foram percebidas situações que necessitem } \\
\text { do conhecimento de dados do usuário de forma } \\
\text { abusiva. O site apenas solicita os dados do } \\
\text { usuário no momento da finalização da compra e } \\
\text { não exige dados pessoais em momentos } \\
\text { desnecessários. }\end{array}$ & Atende \\
\hline
\end{tabular}




\section{(C) 1 (150}

O layout do site é bastante deficiente quanto ao seu redimensionamento, mesmo em resoluções para notebook, fazendo os elementos saírem do campo visual, em especial a área de visualização Compatibilidade de vídeos. Na compatibilidade para tablet $\mathrm{e}$ smartphones, o layout é extremamente prejudicado. Este problema dificulta a navegação no site. O site não é compatível com outros idiomas e apresenta conteúdo apenas em inglês.
Não atende (Severidade grave)

Geralmente, o usuário navega no site de forma fácil e clara e consegue localizar o conteúdo facilmente; a barra de navegação é simples, os links no rodapé funcionam como um mapa do site e o sistema de busca responde como esperado. No entanto, o site apresenta deficiência na organização da exibição de navegação a partir

\section{Compatibilidade /Navegação}

das subseções, principalmente na página Support. Nela, além de links que não funcionam, os links para o fórum ou FAQ fazem o usuário perder a referência da página anterior. Na mesma página, os links para Knowledge Base e Developer Support são direcionados para sites diferentes, que são carregados na mesma janela, fazendo o usuário sair repentinamente da janela em que estava.
Não atende (Severidade Grave) e Navegação não atende (Severidade Maior)

\section{Compatibilidade/ Tratamento de erros}

Após o usuário realizar a escolha do produto que deseja comprar, mesmo não estando logado, o usuário pode acessar o site quando desejar e os dados de compra são mantidos salvos. No entanto, o site comete alguns erros, como por exemplo: No acesso ao login na home, caso o usuário digite algum errado, a tela apenas limpa os campos, mas oferece feedback de erro de digitação; O campo de pesquisa da seção Support não funciona e não indica nenhuma informação de uso.
Não atende (Severidade Grave) Navegação - Não Atende (Severidade Maior) Tratamento de Erros - Não Atende (Severidade Maior) 


\section{(C) 1 ]}

O site é bastante consistente no uso dos padrões externos e consistência interna entre as páginas.

Foi observado apenas um problema de consistência interna no acesso à wiki page (Developer Support) e na Knowledge Base em que na mesma janela é apresentado outro site totalmente diferente. Com relação as consistências com a web, o funcionamento dos

Consistência e Contraste inputs de texto causam estranheza, pois o campo de preenchimento não é claro o suficiente para realizar o clique. Também foram percebidos problemas na movimentação dos menus suspensos que se sobrepõem ao conteúdo do site, normalmente espera-se que ao clicar fora do menu, este se feche automaticamente. Mas, o menu permanece aberto até que o usuário click novamente no botão que aciona o menu ou no "x".

\section{Não Atende \\ (Severidade Menor)}

\section{Design Visual}

O site apresenta um design visual coerente com o temática e a página é limpa e atrativa. No entanto, foram observados alguns problemas na baixa qualidade de algumas imagens de produtos na página Store e dos produtos que estão em destaque na página inicial: algumas imagens possuem configuração inadequada ou baixa qualidade, também apresentam aspectos de

Não Atende (Severidade Cosmético) borradas ou serrilhadas. Isso pode causar sensação de má impressão sobre a seriedade do site e desconfiança de usuários mais atentos.

\footnotetext{
Tabela 1. Resultado da avaliação segundo As Dez Orientações Web. Fonte: Elaborada pelo autor, com base na pesquisa realizada
}

De acordo com a avaliação baseada nas Dez Orientações da Web ficou constatado que o site não atende satisfatoriamente 5 das 10 orientações. Entre os problemas listados, apenas as orientações sobre Compatibilidade foram apontadas como Grave. Algumas questões da Navegação e tratamento de erros receberam a severidade Maior. Ainda foram identificadas algumas falhas de severidade de grau Menor e Cosmético nas orientações sobre Consistência, Contraste e Design Visual. 


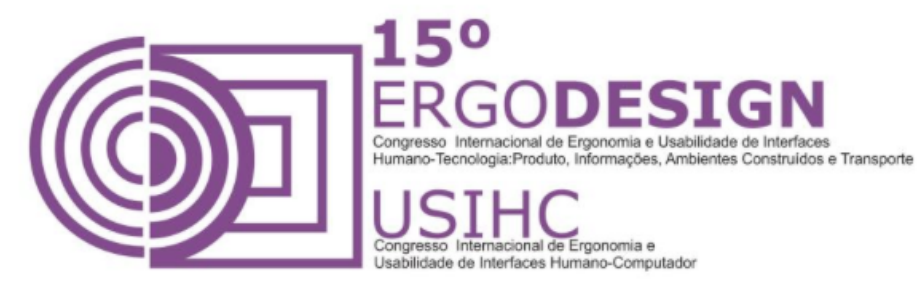

\section{SUGESTÕES}

É possível perceber que a maior parte dos problemas de usabilidade encontrados no site, não são graves ao ponto de impedirem o acesso e o entendimento das informações principais. A maior recomendação de correção no entanto, está na compatibilidade para o acesso através de dispositivos com telas pequenas como tablets e smartphones, especialmente tendo em vista que estes aparelhos são extremamente utilizados para acesso a internet nos dias de hoje. Sendo assim, é extremamente necessário que este problema de usabilidade seja corrigido.

Diante de todos os problemas encontrados, listamos algumas soluções a seguir que podem melhorar a usabilidade do site, baseadas nas falhas identificadas por meio desta pesquisa.

- Compatibilidade: Layout adaptável para diferentes telas desktop e mobile;

- Tratamento de Erros: Mensagens de erro de feedback para o acesso do login;

- Tratamento de Erros: Correção do campo de pesquisa por suporte;

- Tratamento de Erros: Oferta de espaço para contatos por e-mail;

- Tratamento de Erros: Atualização ou correção dos links relacionados aos vídeos com falhas de execução;

- Consistência e Contraste: Padronização do comportamento dos menus suspensos;

- Consistência e Contraste: Melhor delimitação da área de click dos inputs;

- Consistência e Contraste: Melhor contraste dos botões de "+" que ficam sobre a imagem do produto Emotiv Epoc;

- Consistência e Contraste; Navegação: Carregamento de outros site devem ser realizados em outras janelas no browser (Exemplo: Knowledge Base e Developer Support);

- Navegação: Inserir o recurso de migalha de pão para facilitar a localização (em especial para os links acessados a partir de Support);

- Design Visual: Melhora da qualidade das imagens e dos recorte referentes aos produtos e acessórios.

\section{CONCLUSÃO}

Através da análise minuciosa da página web do produto EMOTIV EPOC, tivemos a oportunidade de conhecer detalhadamente esta importante ferramenta de interação. Foi possível também observar e realizar comparações por meio das Dez Orientações da Web de Brinck, T.,Gergle, D. and Wood, S.D. (2002) e da Avaliação Heurística segundo os critérios de Nielsen (1993). Estas foram ferramentas essenciais para a compreensão da dinâmica de interação do usuário e ferramentas web. Através deste estudo foi possível oferecer sugestões para que a qualidade da homepage do produto seja melhorada e ofereça um desempenho satisfatório para os usuários e sirva de bom exemplo para outros sites na web.

Com as dinâmicas de análise de usabilidade escolhidas e aplicadas na pesquisa, foi possível diagnosticar outros problemas que não haviam sido percebidos pelos autores. Portanto, é notável a importância da análise realizada pelos especialistas para que os problemas da 


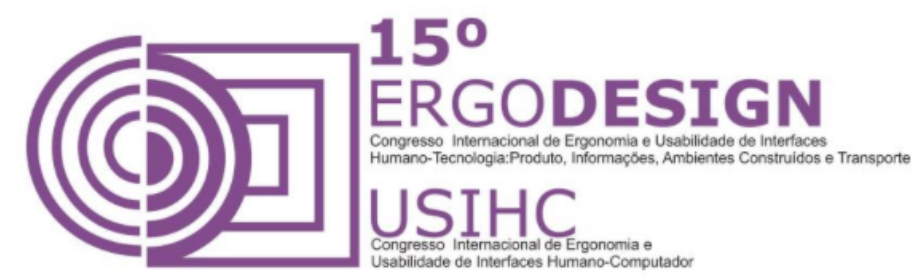

webpage sejam identificado, analisados e possam ser corrigidos.

Concluímos que o site atende cinco das Dez Orientações da Web de Brinck, T.,Gergle, D. and Wood, S.D. (2002), bem como grande parte das Heurísticas de Nielsen. Entretanto, a maioria dos problemas existentes poderiam ser facilmente solucionados para se adequar aos padrões da usabilidade do sistema e consequentemente atender as necessidades de interação do usuário.

\section{REFERÊNCIAS BIBLIOGRÁFICAS}

BRINCK, T., GERGLE, D., \& WOOD, S. D. Usability for the Web: Designing websites that work (1st ed.). San Francisco: Morgan KaufmannPublishers. 2002.

CYBIS, Walter de Abreu; BETIOL, Adriana Holtz; FAUST, Richard. Ergonomia e Usabilidade: conhecimentos, métodos e aplicações. São Paulo: Novatec Editora, 2007.

ESFAHANI, E. \& SUNDARARAJAN, V. Using Brain-Computer Interfaces to detect human satisfaction in Human-Robot Interaction. International Journal of Humanoid Robotics 08(01): 87-101. DOI: 10.11

42/S021984361 1002356. 2011.

FALCÃO, Christianne; MARCELO Soares. Ergonomics, Usability and Virtual Reality: a review applied to consumer product. In: Rebelo, F. e Soares, M.M. Advances in usability evaluation. Part II. Boca Raton, CRC Press, p. 297-306. 2012.

JORDAN, Patrick W. An introduction to usability. Taylor \& Francis: USA. 1998.

ROEPKE, Giorgia Amir Longo. et. al. A importância da ambientação na avaliação da usabilidade de produtos. In: Anais II Conferência Internacional de Integração do Design, Engenharia e Gestão para a inovação, Florianópolis, S.C. p. 21-23, 2012.

LEVENTHAL, Laura; BARNES, Julie.. Usability Engineering: Process, Products and Examples. New Jersey: Pearson Education, Inc. 2008.

NIELSEN, Jakob. Usability Engineering. Boston: Academic Press. 1993 